\section{Prophylaxis for aspiration pneumonitis}

Richard L. McCammon MD
It would be extremely misleading to leave the impression that pharmacological prophylaxis is a substitute for sound judgement and good anaesthetic technique. Yet, existing reports demonstrate that significant morbidity and occasional death all too commonly still arise secondary to the unpredictable event of aspiration. ${ }^{l}$ The primary purpose of this refresher course is to review the pharmacology, efficacy and safety of those drugs which are utilized clinically to alter the volume and/or character of gastric fluid contents. Although documentation is lacking, it is hoped that administration of these drugs will lessen either the incidence or severity of aspiration pneumonitis.

Factors affecting the severity of aspiration The acidity of the aspirate is probably the most important factor contributing to the severity of pneumonitis. In numerous animal models, increasing acidity, whether alone or in combination with food particles, results in increasing tracheal mucosal and lung parenchymal damage. ${ }^{2-4}$ The literature has been replete, however, with the suggestion that an aspirate with a pH greater than 2.5 is relatively benign. Several anecdotal reports as well as recent animal work refute this concept. ${ }^{5-7}$ In fact, the initial physiologic derangement may be just as severe and potentially as lethal. Nevertheless, recovery and healing rates appear to be faster if acidity is reduced.

In this same light, there has been propagation in our literature of the notion that a volume of aspirate less than $0.4 \mathrm{ml} \cdot \mathrm{kg}^{-1}$ (20 to $25 \mathrm{ml}$ in an adult) is relatively safe. Perhaps just as misleading is the converse of this statement - that an aspirate volume exceeding this derived number if uniformly fatal. The concept of a "critical" volume was based on work done in rhesus monkeys in which the aspirated fluid was highly acidic. ${ }^{8}$ In fact, recent work in rats demonstrated that the critical volume depends on the $\mathrm{pH}$ of the apirate. Even low volumes have a high mortality rate if the $\mathrm{pH}$ is low; whereas higher volumes than noted above can be tolerated if the gastric fluid is effectively buffered. ${ }^{9}$

Aspiration of particulate matter such as partially digested food particles has also been known for some time to result in severe pulmonary physiologic derangements. ${ }^{10}$ Such aspirates, in addition to increasing shunt fraction and decreasing arterial oxygen tension, often result in alveolar hypoventilation with accompanying hypercarbia. In the long term, a granulomatous response develops around these particles. Similarly, bacterial contamination of an aspirate, as may occur in a patient with a bowel obstruction, is associated with a very high mortality rate. ${ }^{11}$

Finally, experience in both fresh and salt water drowning victims have demonstrated the importance of the tonicity of an aspirate. Recent work in dogs reconfirmed that as osmolarity of the aspirate increases, so too does the degree of pulmonary physiologic derangement. ${ }^{12}$ It thus becomes apparent that multiple factors influence the significance of an aspirate.

\section{Who is at risk?}

One should ask not only who is at risk for aspiration but also who is at risk for developing a severe pneumonitis should aspiration occur? Clinical experience and common sense tells us that the "prepared", fasted adult or paediatric patient does not present the same risk for aspiration as patients with known anatomic or physiologic disturbances. This group of high risk patients would include patients with reduced levels of consciousness, abnormalities in their swallowing mechanism, oesophageal pathology, incompetence of the gastroesophageal junction, delayed gastric emptying,

Department of Anesthesia, Indiana University School of Medicine, Indianapolis, Indiana, 46223. 
or with material in the stomach. A very high percentage of prepared patients however present to surgery with gastric contents of a volume and acidity which would result in significant pneumonitis should aspiration occur. ${ }^{13}$ In considering the following discussion you should weigh the unpredictability of aspiration in the perioperative period and the potential beneficial effects of various pharmacologic modalities against the potential risk associated with the drugs themselves. Is aspiration a preventable iatrogenic event? Does every patient deserve some type of pharmacologic prophylaxis in addition to our best anaesthetic technique and judgement?

\section{Drugs used for prophylaxis}

\section{Anticholinergics}

Although anticholinergics are of no value in neutralizing acid present in the stomach at the time of their administration, they should block ongoing gastric acid production since it is in part controlled through an acetylcholine effect. Thus, their inclusion with preoperative medicants would conceivably decrease gastric fluid volume and acidity at the time of induction of anaesthesia. In fact, their efficacy has proven to be dose- and time-dependent, greatest with glycopyrrolate, and most effective in paediatric and obstetrical patients. ${ }^{14-16}$ Their efficacy in clinically accepted doses in adult patients scheduled for elective surgery has proved to be of limited benefit. Although potentiation of the inhibitory action of cimetidine on gastric acid secretion by simultaneous administration of anticholinergics has been reported in patients with duodenal ulcers, this interaction has not been demonstrated in elective surgical patients. ${ }^{17,18}$ Interestingly, markedly beneficial effects have been demonstrated when anticholinergics were given with antacids. ${ }^{19}$

With regard to the overall prevention of aspiration, anticholinergics have some potential drawbacks associated with their administration. First, they may decrease lower oesophageal sphincter pressure, thus increasing the likelihood of regurgitation. This effect is dose-related and most pronounced after intravenous administration. ${ }^{20}$ Second, anticholinergics can counteract the desirable effects of metoclopramide on gastric peristalsis and the lower oesophageal sphincter. ${ }^{21}$

\section{Antacids}

Many investigators have demonstrated that particulate antacids are effective in raising gastric fluid $\mathrm{pH}$ in a high percentage of both obstetrical and surgical patients. ${ }^{8,22,23}$ Indeed, their effectiveness in raising $\mathrm{pH}$ depends on (1) the volume and $\mathrm{pH}$ of the gastric contents present at the time of their administration, (2) the frequency and timing of antacid administration, (3) the type and amount of antacid given, (4) what manoeuvres, if any, are done to promote mixing of the antacid with the gastric contents, (5) the intrinsic gastric motility present at the time of antacid administration, and (6) the rate of ongoing gastric acid production.

Despite their overall effectiveness in raising gastric fluid $\mathrm{pH}$, particulate antacids have come under criticism in the last few years for two primary reasons. First, their administration may increase gastric volume. As an example, routine q2-4 hour dosing with antacids became common practice on many obstetrical wards because of the unpredictability of emergency induction of anaesthesia as well as concem over acid rebound (an increase in $\mathrm{pH}$ over basal levels four or more hours following antacid neutralization). This practice has fallen into disfavour since it has been appreciated that in the labouring patient (particularly those receiving narcotics for pain), gastric motility is slowed. ${ }^{24}$ Thus, such a practice could lead to significant increases in gastric volume. Yet, the impact of a single dose of an antacid on gastric volume in an individual patient is highly variable. In fact, in patients with normal gastric motility, antacids not only may not change volume but may decrease it, because the duodenum can accept neutral gastric contents more rapidly than highly acidic contents. ${ }^{25}$

The second major criticism is that particulate antacid aspiration not only results in initial pulmonary derangement as severe as a highly acidic aspirate but also histologic abnormalities for as long as one month following aspiration. ${ }^{26}$ In fact, these chronic granulomatous responses were not noted in study groups with acid aspirates.

Thus an intense interest has been sparked in soluble antacids. The two soluble antacids most investigated clinically to date are 0.3 molar sodium citrate (not available commercially, thus it must be prepared by your hospital pharmacy) and Bicitra (Willen Drug Co). These two antacid preparations contain approximately the same amount of sodium 
citrate and despite differing $\mathrm{pH}$ 's (Bicitra is more acidic since it contains citric acid in addition to sodium citrate) they have similar neutralizing capacities. ${ }^{27}$

Are these compounds as effective as particulate antacids in raising gastric fluid $\mathrm{pH}$ and are there any advantages for their use? The preponderance of evidence suggests that soluble antacid are as effective as particulate antacids in raising gastric fluid $\mathrm{pH}$ in both elective and emergency surgical patients, if given within 15 to 60 minutes of induction of anaesthesia. ${ }^{28-33}$ In the reports where their efficacy has been questioned, the interval between their ingestion and the induction of anaesthesia (gastric sampling) usually has been greater than 60 minutes. ${ }^{33-35}$ Recent work has demonstrated that this is most likely due to the fact that if normal gastric motility is present at the time of antacid administration, the soluble antacids may pass on through the gastrointestinal tract (thus their effect dissipates) while gastric acid production continues. ${ }^{36}$

Are there advantages? Soluble antacids mix with gastric contents more readily than particulate antacids. ${ }^{37}$ Thus, the need to have the patient roll from side to side to promote mixing of gastric contents with the antacid may be lessened. In addition, some studies have indicated that aspiration of soluble antacids, compared with particulate antacids, though resulting in just as severe initial pulmonary physiological derangements, may be associated with more rapid recovery and less long-term histologic changes. ${ }^{38,39}$

\section{Histamine $\mathrm{H} 2$ receptor antagonists}

It is well documented that the $\mathrm{H} 2$ blockers decrease nocturnal, basal, and meal stimulated gastric acid production by competitively inhibiting the action of histamine on the $\mathrm{H} 2$ receptor of the gastric parietal cell. In contrast, they have no apparent effect on gastric emptying time or on lower oesophageal sphincter pressure. Such findings, as would be expected, sparked an absolute plethora of work on the efficacy of these compounds in increasing gastric fluid $\mathrm{pH}$ or decreasing gastric volume using multiple approaches and in numerous subsets of surgical patients. The following comments attempt to summarize this mass of data on cimetidine (Tagamet-Smith Kline \& French), the most widely studied $\mathrm{H} 2$ blocker.

First, the preoperative administration of cimeti- dine has in a dose related manner, been shown to decrease significantly the acidity of gastric contents in samples taken immediately following the induction of anaesthesia. ${ }^{40}$ Second, timing of administration is important. Oral administrtion takes 60 to 90 minutes before a significant effect can be demonstrated and this effect seems to wane by four to six hours. ${ }^{41}$ In contrast, intravenous administration has been demonstrated to be efficacious 45 to 60 minutes following injection although the duration of action is not necessarily any longer than following oral administration. ${ }^{42}$ Parenteral administration results in earlier and higher initial blood levels and results in a higher percentage of patients with $\mathrm{pH}$ values greater than 2.5 at induction of anaesthesia. ${ }^{43}$ Multiple dose regimens (a dose the evening before and the morning of surgery) are more effective than single morning doses.

One- or two-dose cimetidine therapy has an excellent safety record. Such short-term administration inhibits the mixed function oxidase system and decreases liver blood flow. ${ }^{44,45}$ These effects can result in higher blood levels and more pronounced effects of drugs which depend on the liver for their clearance. Indeed, it is well documented that co-administration of cimetidine will prolong the elimination half-lifes of warfarin, diazepam, theophylline, phenytoin, and possibly propranolol. Likewise, there are a few reports in which cimetidine has been purported to contribute to delayed awakening from anaesthesia by this mechanism. ${ }^{46,47}$ There is a theoretical, if not real, concern that cimetidine therapy can aggravate bronchospasm in asthmatics by allowing histamine to have an unopposed $\mathrm{H} 1$ effect. ${ }^{48}$ Finally, rapid intravenous administration of relatively large doses $(600$ $\mathrm{mg}$ ) of cimetidine has been reported to cause hypotension and dysrhythmias. ${ }^{49}$

Cimetidine has also proved to be safe in obstetrical patients. Two reports have not demonstrated any maternal complications attributable to cimetidine treatment nor have any adverse effects been noted in infants whose mothers received cimetidine (based on Apgar and neurobehavourial scores). ${ }^{50.51}$

Does the newly available $\mathrm{H} 2$ antagonist - ranitidine (Zantac - Glaxo) - offer any significant advantages over cimetidine? Purported advantages are ranitidine's greater potency, longer duration of action (six to eight hours), lower incidence of side effects, and lesser degree of inhibition of the mixed 
function oxidase system. ${ }^{44}$ Its onset of action is probably no more rapid than that of cimetidine and therefore it suffers from the same limitations in the emergency situation. Its efficacy in raising gastric $\mathrm{pH}$ has proven to be similar to or slightly better than that of cimetidine. ${ }^{52-55}$ The prolonged duration of action is well documented and offers a distinct advantage. A dose on the eve of surgery should suppress acid production throughout the night while a morning dose should last long enough to provide good conditions well into the emergence/recovery period. It seems increasingly obvious however that the latter claims of fewer side effects and less inhibition of the mixed function oxidase system may be overstated. ${ }^{56}$

Co-administration of antacids or metoclopramide with $\mathrm{H} 2$ blockers has been shown to reduce the bioavailability of the $\mathrm{H} 2$ antagonist secondary to reduced absorption. ${ }^{57,58}$ Nevertheless, co-administration of $\mathrm{H} 2$ blockers and metoclopramide has been shown to have greater efficacy in favourably altering both the $\mathrm{pH}$ and volume of gastric fluid than either drug alone..$^{59-62}$

\section{Metoclopramide}

Metoclopramide (Reglan - A.H. Robins) is a chlobenzamide derivative which possesses three characteristics which make it potentially very useful in anaesthesia. It increases the lower oesophageal sphincter pressure, speeds gastric emptying time, and has antiemetic properties. ${ }^{63,64}$ It has no direct effect on gastric fluid $\mathrm{pH}$. As such it represents a markedly different approach to aspiration prophylaxis than the drugs discussed above.

Several investigators have noted that either oral or parenteral administration of metoclopramide to patients scheduled for elective or emergency surgery decreases the volume of gastric contents. ${ }^{65-68}$ Others have not been able to duplicate these findings ${ }^{69}$ Some of the discrepancies may be dose-related. Another factor which comes into play is the highly variable blood levels attained following oral administration, due to the wide range in first pass hepatic metabolism of metoclopramide. Differences in observed effects may also arise from differences in the basal state of gastrointestinal motility present at the time of administration of metoclopramide. That is, it is probable that metoclopramide is most effective in modifying gastric motility when this is already impaired by other factors.

Of interest to anaesthetists is the observation that metoclopramide may not reliably reverse narcoticinduced inhibition of gastric motility. ${ }^{70}$ Similarly, metoclopramide may be more effective at emptying a "light" or liquid meal than a solid meal." Although a significant decrease in gastric volume can be demonstrated within 20 minutes of administration of metoclopramide, it is recommended to wait at least 30 minutes after a "light" meal and up to 75 to 90 minutes after "heavier" meals for a reliable effect following metoclopramide.

Likewise, it has been demonstrated that metoclopramide increases lower oesophageal sphincter pressure and barrier pressure (the pressure difference between intragastric pressure and lower oesophageal sphincter pressure) in both nonpregnant and pregnant women with and without symptoms of oesophageal reflux. ${ }^{72}$ Thus, the likelihood of passive regurgitation should be reduced following metoclopramide. The efficacy of metoclopramide as an antiemetic in anaesthesia has proven to be highly variable.

In the dose range commonly employed (10 to $20 \mathrm{mg}$ ), metoclopramide is relatively safe. Higher dosages, particularly in children, have been associated with agitation, irritability and extrapyramidal symptoms. ${ }^{73}$ To date, when given to parturients, metoclopramide has been shown not to impede the progress of labour nor adversely affect Apgar neurobehavioural scores. ${ }^{74}$

\section{References}

1 Hunter AR, Moir DD. Editorial - confidential enquiry into matemal deaths. Br J Anaesth 1983; 55: 267-9.

2 Teabeaut $J R$. Aspiration of gastric contents - an experimental study. Am J Pathol 1952; 28: 51-67

3 Awe WC, Fletcher WS, Jacob $S W$. The pathophysiology of aspiration pneumonitis. Surgery 1966; 60: 232-9.

4 Wynne JW, Ramphal R, Hood CI. Tracheal mucosal damage after aspiration. Am Rev Respir Dis 1981; 124: 728-31

5 Taylor $G$. Acid pulmonary aspiration syndrome after antacids. Br J Anaesth 1975; 47: 615-6.

6 Bond VK, Stoelting RK, Gupta CD. Pulmonary aspiration syndrome after inhalation of gastric fluid 
containing antacids. Anesthesiology 1979; 51: 452-3.

7 Schwartz DJ, Wynne JW, Gibbs CP, Hood CI, Kuch $E J$. The pulmonary consequences of aspiration of gastric contents at $\mathrm{pH}$ values greater than 2.5 . Am Rev Respir Dis 1980; 121: 119-26.

8 Roberts $R B$, Shirley $M A$. Reducing the risk of acid aspiration during Cesarean section. Anesth Analg 1974; 53: 859-68.

9 James CF, Modell JH, Gibbs CP, Kuck EJ, Ruiz $B C$. Pulmonary aspiration - effects of volume and $\mathrm{pH}$ in the rat. Anesth Analg 1984; 63: 665-8.

10 Wynne JW, DeMarco FJ, Hood CI. Physiological effect of corticosteroids in food stuff aspiration. Arch Surg 1981; 116: 46-9.

11 Wynne JW, Modell JH. Respiratory aspiration of stomach contents. Ann Intern Med 1977; 87: 46674.

12 Rogers MA, Toung JK, Gurtner G et al. The effects of osmolarity of pulmonary damage in aspiration. Anesthesiology 1984; 61: A490.

13 Manchikanti L. Colliver J, Marrero TC, Roush JR. Assessment of age-related acid aspiration risk factors in pediatric, adult, and geriatric patients. Anesth Analg 1985; 64: 11-7.

14 Salem MR, Wong $Y$, Mani $M$, Bennett EJ, Toyama $T$. Premedicant drugs and gastric juice $\mathrm{pH}$ and volume in pediatric patients. Anesthesiology 1976; 44: 216-9.

15 Baraka A, Saab M, Salem MR, Winnie AP. Control of gastric acidity by glycopyrrolate premedication in the parturient. Anesth Analg 1977; 56: 642-5.

16 Stoelting $R K$. Responses to atropine, glycopyrrolate, and riopan on gastric fluid $\mathrm{pH}$ and volume in adult patients. Anesthesiology 1978; 48: 367-9.

17 Richardson CT. Effect of $\mathrm{H} 2$-receptor anatagonists on gastric acid secretion and serum gastrin concentration. Gastroenterology 1978; 74: 366-70.

18 Manchikanti L, Roush JR. Effect of preanesthetic glycopyrrolate and cimetidine on gastric fluid $\mathrm{pH}$ and volume in outpatients. Anesth Analg 1984; 63: 40-6.

19 Dewan DM. Antacid-anticholinergic regimens in patients undergoing elective Caesarean section. Can Anaesth Soc J 1982; 29: 27-30.

20 Cotton $R B$, Smith $G$. The lower oesophageal sphincter and anaesthesia. Br J Anaesth 1984; 56: $37-46$.

21 Cotton $R B$, Smith $G$. Single and combined effects of atropine and metoclopramide on the lower oesophageal sphincter pressure. Br J Anaesth 1981; 53: 869-72.

22 Taylor $G$, Pryse-Davies $J$. The prophylactic use of antacids in the prevention of the acid pulmonary aspiration syndrome. Lancet 1966; 1: 288-91,

23 White A, Clark R, Thompson DS. Preoperative oral antacid therapy for patients requiring emergency surgery. So Med J 1978; 71: 177-9.

24 Davison JS, Davison M, Hay DM. Gastric emptying time in late pregnancy and labour. J Obstet Gynaecol Br Common 1970; 77: 37-41.

25 Hunt JN, Knox MT. The slowing of gastric emptying of four strong acids and three weak acids. J Physiol 1972; 222: 187-9.

26 Gibbs CP, Schwartz KJ, Wynne JW, Hood CI, Kuck EJ. Antacid pulmonary aspiration in the dog. Anesthesiology $1979 ; 51: 380-5$.

27 James $C F$, Gibbs $C P$. An evaluation of sodium citrate solutions. Anesth Analg 1983; 62: 241.

28 Lahira SK, Thomas TA, Hodgson RM. Single-dose antacid therapy for the prevention of Mendelson's syndrome. Br J Anaesth 1973; 45: 1143-6.

29 Foulkes E, Jenkins LC. A comparative evaluation of cimetidine and sodium citrate to decrease gastric acidity. Can Anaesth Soc J 1981; 28: 29-32.

30 Gibbs CP. Spohr L, Schmidt D. The effectiveness of sodium citrate as an antacid. Anesthesiology 1982; 57: 44-6.

31 Viegas OJ, Ravindran RS, Schumacker CA. Gastric fluid $\mathrm{pH}$ in patients receiving sodium citrate. Anesth Analg 1981; 60: 521-3.

32 Gibbs CP, Banner TC. Effectiveness of Bicitra as a preoperative antacid. Anesthesiology 1984; 61: 97-9.

33 Dewan DM, Floyd HM, Thistlewood JM, Bogard $T D$, Spielman $F J$. Sodium citrate pretreatment in elective Cesarean section patients. Anesth Analg 1985; 64: 34-7.

34 Hester $J B$, Heath $M L$. Pulmonary acid aspiration syndrome. Br J Anaesth 1977; 49: 595-9.

35 Dewan DM, Writer WDR, Wheeler AS et al. Sodium citrate premedication in elective Caesarean section patients. Can Anaesth Soc J 1982; 29: 355 736.

$36 O^{\prime}$ Sullivan GM, Bullingham RE. Does twice the volume of antacid have twice the effect in pregnant women at term? Anesth Analg 1984; 63: 752-6.

37 Holdsworth JD, Johnson $K$, Mascall G, Roulston 
RG, Tomlinson PA. Mixing of antacids with stomach contents. Anaesthesia 1980; 35: 641-50.

38 Gibbs CP, Hempling RE, Wynne JW. Antacid pulmonary aspiration. Anesthesiology 1979; 51: S290.

39 Eyler SW, Cullen BR, Murphy ME, Welch WD. Antacid aspiration in rabbits: a comparison of mylanta and Bicitra. Anesth Analg 1982; 61: 288-92.

40 Manchikanti L, Kraus JW, Edds SP. Cimetidine and related drugs in anesthesia. Anesth Analg 1982; 61: 595-608.

41 Husemeyer RP, Davenport HT, Rajasenkran T. Cimetidine as a single oral dose for prophylaxis against Mendelson's syndrome. Anaesthesia 1978; 33: 775-8.

42 Coombs DW, Hooper D, Colion T. Preanesthetic cimetidine alteration of gastric fluid volume and $\mathrm{pH}$. Anesth Analg 1979; 58: 183-8.

43 Weber L, Hirshman CA. Cimetidine for prophylaxis of aspiration pneumonitis. Anesth Analg 1979; 58 : 426-8.

44 Breen $K J$, Bury $R$, Desmond PV et al. Effects of cimetidine and ranitidine on hepatic drug metabolism. Clin Pharmacol Ther 1982; 31: 297-300.

45 Feely J, Wilkinson GR, Alastair J, Wood JJ. Reduction of liver blood flow and propranolol metabolism by cimetidine. N Engl J Med 1981; 304: 692-5.

46 Lam AM, Parkin JA. Cimetidine and prolonged postoperative somnolence. Can Anaesth Soc J 1981; 28: 450-2.

47 Viegas OJ, Sroops Ca, Ravindran RS. Reversal of cimetidine-induced postoperative somnolence. Anesthesiology Review 1982; 9: 30-2

48 Nathan RA, Segall N, Glover GC, Schacke AL. The effects of $\mathrm{H} 1$ and $\mathrm{H} 2$ antihistamines of histamine inhalation challenges in asthmatic patients. Am Rev Respir Dis 1979; 120: 1251-8.

49 Cohen J, Weetman AP, Dragie HJ. Life threatening arrhythmias and intravenous cimetidine. Br Med J 1979; $2: 768$

50 Hodgkinson $R$, Glassenberg $R$, Joyce $T H$ et al. Comparison of cimetidine with antacid for safety and effectiveness in reducing gastric acidity before elective Cesarean section. Anesthesiology 1983; 59: 8690.

51 Johnson JR, Moore J, McCaughey W et al. Use of cimetidine as an oral antacid in obstetrical anesthesia. Anesth Analg 1983; 62: 720-6.
52 Francis $R N$, Kwik $R S H$. Oral ranitidine for prophylaxis against Mendelson's syndrome. Anesth Analg 1982; 61: 130-2.

53 Morison DH, Dunn GL, Fargas-Babjak AM et al. A double-blind comparison of cimetidine and ranitidine as prophylaxis against gastric aspiration syndrome. Anesth Analg 1982; 61: 988-92.

54 Durrant JM, Stunin L. Comparative trial of the effect of ranitidine and cimetidine on gastric secretion in fasting patients at induction of anaesthesia. Can Anaesth Soc J 1982; 29: 446-50.

55 Dammann $H G$, Muller $P$, Simon B. Parenteral ranitidine: onset and duration of action. $\mathrm{Br} J$ Anaesth 1982; 54: 123-6.

56 McCarthy DM. Ranitidine or cimetidine? Ann Intern Med 1983; 99: 551-3.

57 Gugler $T$, Brand $M$, Somgyi $A$. Impaired cimetidine absorption due to antacids and metoclopramide. Eur J Clin Pharm 1981; 20: 225-8.

58 Mihaly GW, Marino AT, Webster $L K$ et al. High dose of antacid (Mylanta) reduces bioavailability of ranitidine. Br Med J 1982; 285: 998-9.

59 Manchikanti L, Marrero TC, Roush J. Preanesthetic cimetidine and metoclopramide for acid aspiration prophylaxis in elective surgery. Anesthesiology 1984; 61: 48-54.

60 Solanki DR, Suresh $M$, Ethridge HE. The effects of intravenous cimetidine and metoclopramide on gastric volume and $\mathrm{pH}$. Anesth Analg 1984; 63: 599-602.

61 Manchikanti L, Coliver JA, Marrero TC, Roush JR Tanitidine and metoclopramide for prophylaxis of aspiration pneumonitis in elective surgery. Anesth Analg 1984; 63: 903-10.

62 Rao TLK, Madhavareddy S, Chethagada M, El-Etr $A A$. Metoclopramide and cimetidine to reduce gastric fluid pH and volume. Anesth Analg 1984; 63: 1014-6.

63 Schulze-Delrieu K. Metoclopramide. N Engl J Med 1981; 30: 28-33.

64 Albibi $R, M c C a l l u m T$. Metoclopramide-pharmacology and clinical application. Ann Inten Med 1983; 98: 86-95.

65 Howard FA, Sharp DS. Effect of metoclopramide on gastric emptying during labour. Br. Med J 1973; 1: 446-8.

66 Davies JAH, Howells TH. Management of anesthesia for the full stornach case in the casualty department. Postgrad Med J 1973; 49: 58-63. 
67 Olsson GL, Hallen B. Pharmacological evacuation of the stomach with metoclopramide. Acta Anaesthesiol Scand 1982; 26: 417-20.

68 Wyner J, Cohen SE. Gastric volume in early pregnancy. Anesthesiology 1982; 57: 209-12.

69 Cohen SE, Jasson J, Talafre M, ChauvelotMoacheon L, Barrier G. Does metoclopramide decrease the volume of gastric contents in patients undergoing Cesarean section? Anesthesiology 1984; 61: 604-7.

70 Nimmo WS, Wilson J, Prescont LF. Narcotic analgesia and delayed gastric emptying during labour. Lancet 1975; 1: 890-3.

71 Howells TH, Khanam T, Kreel Let al. Pharmacologic emptying of the stomach with metoclopramide. Br Med J 1971; 5: 558-60.

72 Brock-Utne JG, Dow TGB, Welmen S, Dimopoulos GE, Moshal MG. The effect of metoclopramide on the lower esophageal sphincter in late pregnancy. Anaesth Intensive Care 1978; 6: 26-9.

73 Pinder RM, Brogden RM, Sawyer PR, Speight TM, Avery GS. Metoclopramide - a review of its pharmacological properties and clinical use. Drugs 1976; 12: 81-96.

74 Bylsma-Howell M, McMorland GH, Rurak DW, McErlane B, Axelson TE. Placental transport of metoclopramide: assessment of maternal and neonatal effects. Can Anaesth Soc J 1983; 30: 487-92. 